\title{
Global challenges and local legislations: using GIS maps as an educational tool to mobilize low income residents and bring awareness to local legislators-
} case study

\section{Case report}

With approximately 870 million people of the 7.1 billion people in the world suffering from chronic undernourishment, alleviating hunger is imperative as it burdens societies economically, socially, and politically. Though the majority effected live in underdeveloped countries, there is a rapid rise in developed countries from 13 million in 2004 to 2006 to 16 million in 2012, reversing a steady decrease from 20 million in the early 1990 s. ${ }^{1}$ In the U.S., movement to alleviate food scarcity for vulnerable populations (particularly women and children), has been on the forefront for public health policy since 1974 with the Special Supplemental Nutrition Program for Women, Infants, and Children. ${ }^{2}$ With the continuation of this federal mandate to ensure the well-being of the American underprivileged, local governments struggle to inform their communities on regularly revised WIC packets though education and community mobilization. Aiding needy populations through effective outreach and local policy is a great challenge, especially as there are expectations to do both simultaneously. In Jersey City, food insecurity is a global issue of current local focus where GIS mapping serves as an educational tool to spur both residents and legislators into advocacy.

Jersey City's Department of Health and Human Services (JCDHHS) and undergraduate community health students from New Jersey City University implemented "Cooking Matters", a program designed to provide educational grocery store tours to low-income residents to increase access to healthy foods. The students employed GIS mapping to identify correlations between residents' levels of economic
Volume 2 Issue 6 - 2015

\author{
Dinah Carter \\ Department of Public health policy, George Washington \\ University, USA
}

\begin{abstract}
Correspondence: Dinah Carter, Department of Public health policy, George Washington University, District of Columbia, Washington, USA, Email: dinahcarter8@gmail.com
\end{abstract}

Received: June 19,2015 | Published: November 27, 2015

prosperity and local food distribution businesses. The maps were displayed at community health events for educational purposes. What was found was that the GIS maps assisted with communicating to both targeted residents and policy makers quickly and comprehensively to ultimately motivating advocacy in both parties. Due to the maps' ability to transcend multiple barriers such as language and literacy, they have the capacity to deliver effective services consistently while easily explaining diverse and ever changing complexities. One map can serve as multiple methods as an educational tool to showcase crucial patterns for community engagement and policy development (Figures 1-3).

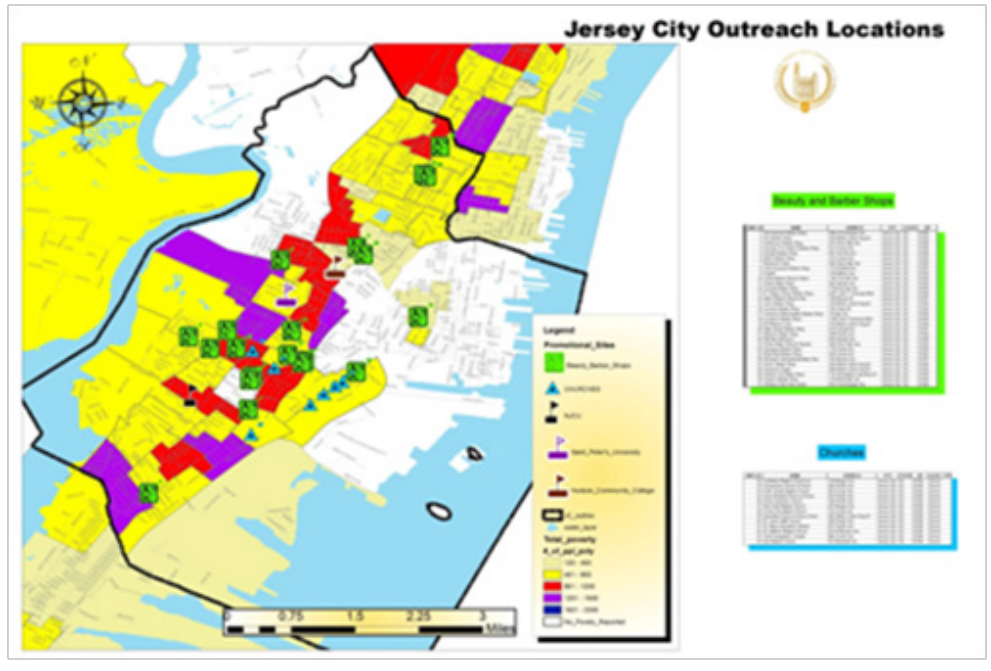

Figure I Jersey City Community Assets \& Outreach Locations. 


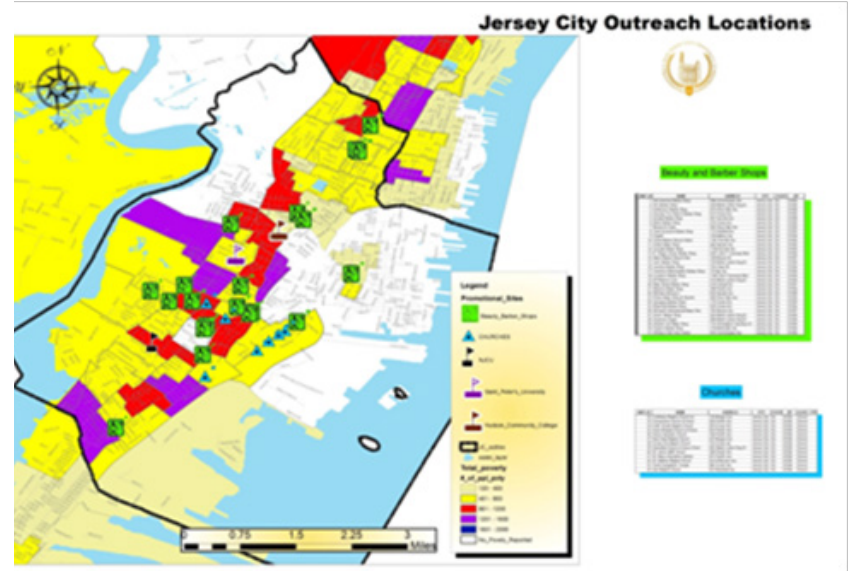

\section{Acknowledgements}

None.

\section{Conflict of interest}

The author declares no conflict of interest.

\section{References}

1. FAO, WFP, IFAD. The State of Food Insecurity in the World 2012. Economic growth is necessary but not sufficient to accelerate reduction of hunger and malnutrition. Rome; 2012.

2. United States Department of Agriculture. Women, infants, and children (WIC). USA; 2015.

Figure 2 Jersey City Community Assets \& Low-Income Fast food Restaurants.

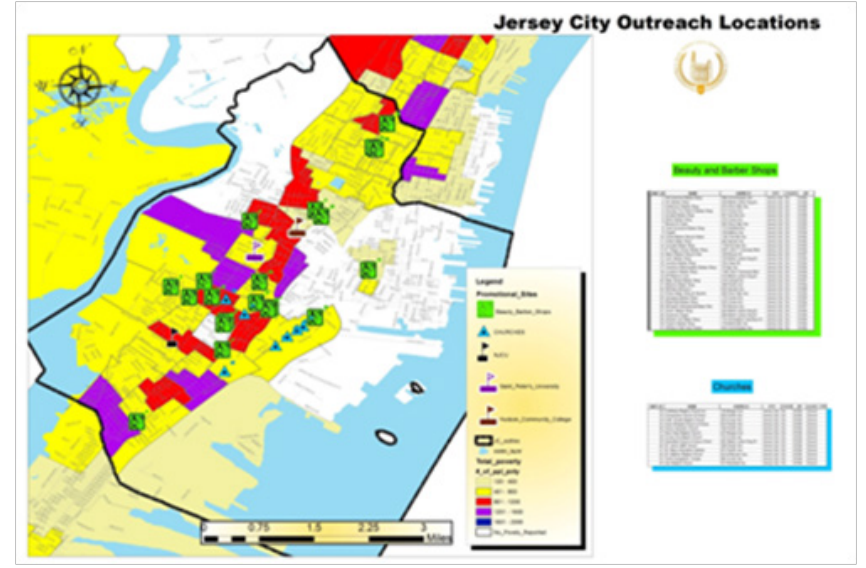

Figure 3 Jersey City Community Assets \& Low Income Supermarkets. 